\title{
A Critical Review of Analytical Methods for Quantification of Cefotaxime
}

\section{Lívia Paganini Consortti \& Hérida Regina Nunes Salgado}

To cite this article: Lívia Paganini Consortti \& Hérida Regina Nunes Salgado (2017) A Critical Review of Analytical Methods for Quantification of Cefotaxime, Critical Reviews in Analytical Chemistry, 47:4, 359-371, DOI: 10.1080/10408347.2017.1298988

To link to this article: https://doi.org/10.1080/10408347.2017.1298988

Accepted author version posted online: 13

Mar 2017.

Published online: 17 Mar 2017.

Submit your article to this journal $\pi$

Џll Article views: 217

Citing articles: 4 View citing articles $[7$ 


\title{
A Critical Review of Analytical Methods for Quantification of Cefotaxime
}

\author{
Lívia Paganini Consortti (D) and Hérida Regina Nunes Salgado \\ Departamento de Fármacos e Medicamentos, Faculdade de Ciências farmacêuticas, Univ. Estadual Paulista, Araraquara, SP, Brazil
}

\begin{abstract}
Bacterial resistance to antibiotics is a growing phenomenon in the world. Considering the relevance of antimicrobials for population and the reduction in the registration of new antimicrobials by regulatory, proper quality control is required in order to minimize the spread of bacterial resistance and ensure the effectiveness of a treatment, as well as safety for the patient. Among the antimicrobials is cefotaxime, a drug belonging to third-generation cephalosporins, which is highly active against Gram-negative bactéria and is used to treat central nervous system infections such as meningitis and septicemia. Due to the critical importance of quality control in regard to drugs and pharmaceutical products, combined with bacterial resistance to antibiotics, this study aims to conduct a detailed review of analytical methods for cefotaxime. Using a critical review of literature, this paper describes the analytical methods published to quantify cefotaxime in different matrices; a large number of methods by HPLC and spectrophotometry were observed. Despite the advantages of the techniques, most methods reported have large environment and occupational impact, which enfatizes the need to adopt green procedures in quantifying cefotaxime.
\end{abstract}

\section{KEYWORDS}

Analytical methods; cefotaxime; HPLC; quality control; review

\section{Introduction}

Bacterial resistance to antimicrobial agents is a phenomenon that occurs following extensive contact of bacteria with antibiotics and their presence in the environment. Until the twentieth century, bacterial resistance was usually restricted to hospitals; however, it can now be identified in different environments where it can affect even healthy individuals (Guimarães et al., 2010).

Faced with the high rate of bacterial resistance to antibiotics, as well as a reduction in the number of drugs approved by the FDA in recent years, it is necessary to develop new drugs, adopt new therapeutic strategies and incorporate cultural changes educating professionals and population (Guimarães et al., 2010; Brooks and Brooks, 2014; Oldifield and Feng, 2014). Antimicrobials have great relevance in the health field since bacterial infections are one of the leading causes of mortality globally (Brito and Cordeiro, 2012).

Among the antibiotics are the cephalosporins, the secondlargest class of $\beta$-lactam antibiotics (Guimarães et al., 2010). Acting to prevent bacterial cell wall synthesis, cephalosporins are considered safe and low-toxicity antimicrobials (Tortora et al., 2012). The existing cephalosporins are classified in five generations according to the action spectrum, stability to $\beta$-lactamases, pharmacokinetics, chemical stability and side effects (Alessio and Salgado, 2012; Vieira et al., 2012; Fernandes et al., 2013; De Marco and Salgado, 2016).

Cefotaxime sodium is included in the third-generation cephalosporins. The major developments in relation to previous generations of cephalosporins are the presence of amplification in the penetration of drugs in Gram-negative bacteria, which contributes to the expansion of the spectrum of action and the development of higher affinity for the site of action (Patrick, 2009). In addition, third-generation antimicrobials reach the central nervous system in significant concentrations, allowing their use in the treatment of meningitis and sepsis by Gramnegative microorganisms (Fernandes et al., 2013).

Given the importance of antibiotics in the global population, these drugs require accurate and reliable quality control. Analytical methods comprise one of the quality control tools in pharmaceutical industry required by regulatory organizations worldwide to verify the suitability of pharmaceutical ingredients and finished products to the established specifications, which can guarantee satisfactory quality of these products. Confirming the pertinence of the products to the specifications, in other words the correct dosage of the pharmaceutics, with implementation of analytical methods that provide reliable results, the patient will have a more effective and safe treatment, minimizing the chances of developing bacterial resistance (ANVISA, 2010).

Cefotaxime is an important third-generation cephalosporin related to its high resistance to $\beta$-lactamases, a bacterial resistance mechanism developed by microorganisms, and for its beneficial activity against numerous aerobic Gram-negative and Gram-positive bacterias when compared to other $\beta$-lactam compounds. It is used effectively in the treatment of meningitis and other severe infections (Brunton et al., 2012). Due to its importance of cefotaxime in therapeutics, reliable quality 
control has a high impact in the efficiency of cefotaxime and bacterial resistance in the hospital environment.

Related to the presented facts, we prepared a large search of analytical methods described for the quantification of cefotaxime in both pharmaceutical and general matrices.

\section{Cefotaxime}

Sodium cefotaxime (Figure 1) is a third-generation cephalosporin that binds irreversibly to the transpeptidase enzyme, responsible for catalyzing the peptide bonds synthesis of the bacteria wall. Following this binding, the structure is impaired, leading to bacterial cell lysis (Tortora et al., 2012).

In North America and Europe, cefotaxime is commercially available as a lyophilized powder that can be administrated via the intramuscular or intravenous routes, as $1-4 \mathrm{~g}$ of cefotaxime per day in two or three doses; in case of severe infection, 10$12 \mathrm{~g}$ per day may be administrated. It is used mainly in the treatment of meningitis caused by Haemophilus influenzae, Streptococcus pneumoniae sensitive to penicillin, Neisseria meningitidis and other infections of the central nervous system (Korolkovas, 2010). The reference product is Claforan ${ }^{\circledR}$, which is produced by Sanofi-Aventis LLC (ANVISA, 2016).

When administered intravenously, the plasma half-life of cefotaxime is approximately 1 hour and when administered intramuscularly, it is approximately 1.5 hours. About $25-40 \%$ of cefotaxime binds to plasma proteins (Patel et al., 1995; Brunton et al., 2012). Around $90 \%$ of the administered dose is excreted by the kidneys, $50 \%$ in unchanged form and $20 \%$ as desacetylcefotaxime (the main metabolite of cefotaxime) (Kees et al., 1981). Desacetylcefotaxime is less active than the original molecule, but acts synergistically with cefotaxime against several microorganisms (Ko et al., 1991; Jones, 1995).

Cefotaxime sodium, sodium (6R,7R)-7-[2-(2-amino-4-thiazolyl)glyoxylamido]-3-(hydroxymethyl)-8-oxo-5-thia-1-azabicyclo[4.2.0] oct-2-ene-2-carboxylate $7^{2}$-(Z)-(O-methyloxime), acetate (ester), is a semisynthetic derivative of a drug fermentation product. Its molecular formula is $\mathrm{C}_{16} \mathrm{H}_{16} \mathrm{~N}_{5} \mathrm{NaO}_{7} \mathrm{~S}_{2}$ and its molecular weight is $477.45 \mathrm{~g} / \mathrm{mol}$ (Infarmed, 2005; Society of Japanese Pharmacopeia, 2011; O'Neil, 2013; The Stationary Office, 2014; Council of Europe, 2014; United States Pharmacopeia Convention, 2014).

It is a white or slightly yellowish crystalline powder, and it is hygroscopic. It is freely soluble in water, sparingly soluble in methanol, slightly soluble in ethanol and practically insoluble in organic solvents; it must be stored in a tightly closed container protected from light, at temperatures below $30^{\circ} \mathrm{C}$ (Infarmed, 2005; Society of Japanese Pharmacopeia, 2011;

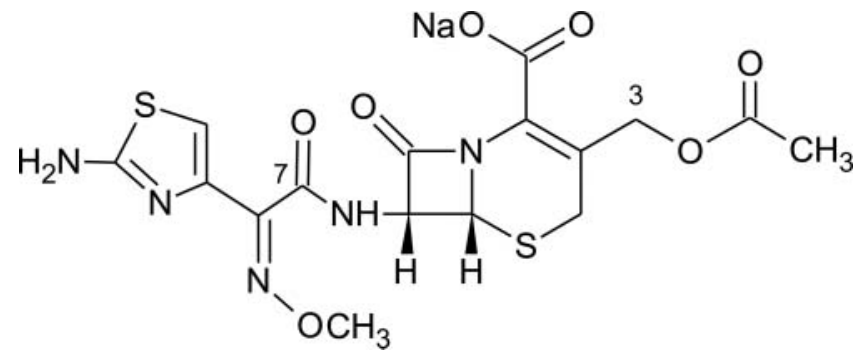

Figure 1. Chemical structure of sodium cefotaxime (CAS 64485-93-4).
O’Neil, 2013; The Stationary Office, 2014; Council of Europe, 2014; United States Pharmacopeia Convention, 2014).

The characteristic chemical grouping of cephalosporin present in cefotaxime is 7-aminocephalosporinic acid, comprising a $\beta$-lactam ring and a dihydrothiazine ring. The characteristic chemical structure of cephalosporins is presented in Figure 2; the group attached to carbon 7 of the basic structure differentiates cefotaxime from the others in the class. In addition, the carbon group linked to position 3 ensures good pharmacokinetic properties such as the transfer to the central nervous system in significant concentrations (Patrick, 2009; Fernandes et al., 2013).

\section{Analytical methods}

The quality control of active pharmaceutical ingredients (APIs) and pharmaceutical products is an important activity embedded in good manufacturing practices within the pharmaceutical industry (ANVISA, 2010). Therefore, the development and validation of new analytical methods and the improvement of existing methods for proper identification and quantification of drugs and pharmaceutical products are of great importance in the industry and the scientific community, to ensure their safety and effectiveness. Thus, research groups have studied analytical methods for the quantification of drugs and cefotaxime sodium in different biological matrices.

Bioassays are relevant for clinical studies, therapeutic drug monitoring (TDM) and individual dose adjustment. Hydrophilic drugs may present daily variations in the plasma concentrations of critically ill patients. In this scenario, the development of bioanalytical methods is essential for the efficacy and safety of the treatment with cefotaxime.

There are some papers describing analytical methods to quantify cefotaxime in many matrices, such as blood, plasma, serum, peritoneal fluid and urine. In the literature, it is possible to find papers that noticed the importance of the development of practical analytical methods to be used in the TDM of cefalosporins.

Yilmaz and Biryol (1998) developed a method of determining cefotaxime by voltammetry. The analysis conditions were: carbon electrode, platinum wire for dosing and calomel electrode and standard solutions for analysis using $0.2 \mathrm{M}$ phosphoric acid as diluent. Quantification by direct titration was developed by Helaleh et al. (1998), where a lyophilized powder of cefotaxime sodium solution at a concentration of $1 \mathrm{mg} / \mathrm{mL}$

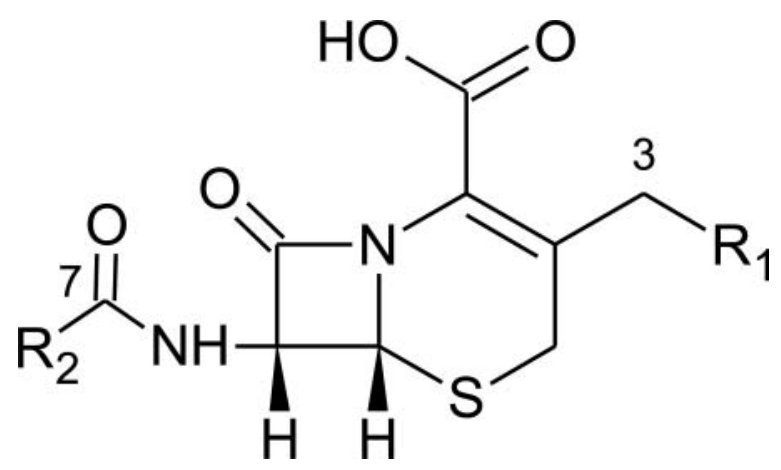

Figure 2. Chemical basic structure of cephalosporins. 
was titrated with potassium iodide and end-point detection conducted with the aid of carbon tetrachloride $0.01 \mathrm{M}$.

Cefotaxime sodium feedstock samples and in pharmaceutical formulations were analyzed by Nassar and collaborators (1996) with the assessment of the utility of N-bromosuccinimide compounds (NBS) and N-chlorosuccinimide (NCS) in determining cefotaxime sodium by colorimetric and titrimetric techniques. The optimal reaction time was 20 minutes and the method had the limit of quantification of $1.5913 \mathrm{mg}$ of cefotaxime.

Methods for determining the assay of cefotaxime sodium and other cephalosporins by capillary electrophoresis are also reported in the literature under different analytical conditions.

Solangi et al. (2007) describe a method of analysis for eight cephalosporins in urine. Fused silica capillary with $57 \mathrm{~cm}$ of total length, $50 \mathrm{~cm}$ of effective length and $75 \mu \mathrm{m}$ internal diameter was used. Sodium tetraborate buffer $\mathrm{pH} 9.0$ separates the cephalosporins with a $30 \mathrm{kV}$ of potential. The detector used was a UV detector at $214 \mathrm{~nm}$. The analysis was performed at $25^{\circ} \mathrm{C}$.

Gáspár et al. (2002a) developed a method for the analysis and stability study of 14 cephalosporins. The analysis was performed with a fused silica capillary having $64.5 \mathrm{~cm}$ of total length, $56 \mathrm{~cm}$ of effective length and internal diameter of $50 \mu \mathrm{m}$ at a temperature of $25^{\circ} \mathrm{C}$. The solution used for the separation was a $25 \mathrm{mM}$ phosphate solution of $\mathrm{pH}$ 6.8. A potential of $125 \mathrm{kV}$ was applied and a UV detector was used at $260 \mathrm{~nm}$.

A method for detection of cefotaxime and its metabolites in plasma was reported by Penalvo et al. (1997). The analysis was performed with a fused silica capillary having $57 \mathrm{~cm}$ of total length, $50 \mathrm{~cm}$ effective length and $75 \mu \mathrm{m}$ internal diameter at a temperature of $5^{\circ} \mathrm{C}$. The solution used for the separation was a solution of dihydrated sodium dihydrogen phosphate with $\mathrm{pH}$ adjusted to 8.0 and $5 \mathrm{M}$ sodium hydroxide solution containing $165 \mathrm{mM}$ sodium dodecyl sulfate. A $25-\mathrm{kV}$ potential was applied, and the detection was performed with a UV detector at $254 \mathrm{~nm}$.

Mrestani et al. (1997) also described a method for the analysis of cephalosporins, but using a fused sílica capillary of $48.5 \mathrm{~cm}$ total length, $40 \mathrm{~cm}$ of effective length and $50 \mu \mathrm{m}$ of internal diameter. The separation was performed with $20 \mathrm{mM}$ phosphate buffer solution of $\mathrm{pH}$ 7.2. A potential of $30 \mathrm{kV}$ was used and the detection was performed using the UV detector at $200 \mathrm{~nm}$. The analysis temperature was $25^{\circ} \mathrm{C}$.

Gáspár et al. (2002b) published another paper reporting the development of a method for quantification of four cephalosporins in samples obtained after neurosurgeries (fluid drained from injury, cerebrospinal fluid, plasma and urine). The fused silica capillary with $48.5 \mathrm{~cm}$ of total length, $40 \mathrm{~cm}$ of effective length and $50 \mu \mathrm{m}$ of internal diameter was used. The separation solution was $25 \mathrm{mM}$ borate buffer solution of $\mathrm{pH}$ 9.2. A potential of $25 \mathrm{kV}$ and a UV detector at $270 \mathrm{~nm}$ were applied. The analysis temperature was $25^{\circ} \mathrm{C}$.

Penalvo et al. (1996) also validated an analytical method for quantification of cefotaxime and its related impurities. A fused silica capillary used had a total length of $57 \mathrm{~cm}$, effective length of $50 \mathrm{~cm}$ and internal diameter of $75 \mu \mathrm{m}$. The solution of $30 \mathrm{mM}$ sodium dihydrogen phosphate of $\mathrm{pH} 7.2$ containing $165 \mathrm{mM}$ sodium dodecyl sulfate was used for the separation. A potential of $15 \mathrm{kV}$ was applied and a UV detector was used at $254 \mathrm{~nm}$. The analysis was performed at a temperature of $25^{\circ} \mathrm{C}$.

Mrestani et al. (1999) published another study for the analysis of nine cephalosporins in urine and bile samples. A fused silica capillary of $57 \mathrm{~cm}$ total length, $50 \mathrm{~cm}$ of effective length and internal diameter of $50 \mu \mathrm{m}$ was used. For the separation, $50 \mathrm{mM}$ citrate buffer solution of $\mathrm{pH} 6$ was used. The potential applied for the analysis was $30 \mathrm{kV}$ and the detector used was a UV detector at $214 \mathrm{~nm}$. The temperature of the analysis was $25^{\circ} \mathrm{C}$.

Lin et al. (2000) published a study of optimization of the separation and migration of cephalosporins in capillary electrophoresis. The best conditions were the following: fused silica capillary with $57 \mathrm{~cm}$ of total length, effective length of $50 \mathrm{~cm}$ and internal diameter of $50 \mu \mathrm{m}$, separation with citrate buffer and atanosulfonic acid monohydrate buffer solution at various $\mathrm{pH}$ 's, $30 \mathrm{kV}$ potential, $\mathrm{UV}$ detector at $214 \mathrm{~nm}$ and temperature of $25^{\circ} \mathrm{C}$.

Finally, Wang et al. (2009) published a study of the determination of cefotaxime and its enantiomers. The analysis conditions used were: a fused silica capillary of effective length of $40 \mathrm{~cm}$ and internal diameter of $75 \mu \mathrm{m}$, separation solution consisting of $75 \mathrm{mM}$ dihydrogen phosphate buffer sodium solution of $\mathrm{pH} 7$, a potential of $20 \mathrm{kV}$, a UV detector at $280 \mathrm{~nm}$ and a temperature of $25^{\circ} \mathrm{C}$.

Methods for the determination of cephalosporins and cefotaxime by spectrophotometry with absorption in light ultraviolet and visible on various biological matrices, in APIs and in pharmaceutical formulations were found in the literature and the main analytical conditions for each one are listed in Table 1. The low cost and simplicity of the technique can justify the extensive use of spectrophotometric analysis in quantifying the drug. Despite advantages, it has a limitation regarding selectivity: interfering with a similar absorption spectrum of the drug can give inaccurate results, which can compromises the reliability of the analysis (Moreno and Salgado, 2008; Moreno and Salgado, 2009; Vieira and Salgado, 2011).

High performance liquid chromatography (HPLC) is one of the most used techniques for the analysis of drugs and formulations. In the literature, increased number of analytical methods to quantify cefotaxime sodium using this technique were found, both for quantification of cefotaxime in drugs and biological matrices. According to the significant number of methods available for cefotaxime determination by HPLC, we could conclude it is the most used technique for quantifying cefotaxime. All analytical methods found, as well as the analysis conditions, are presented in Table 2 .

United States Pharmacopeia Convention (2014) provides monographs for cefotaxime API, injectable solution and lyophilized powder for injection. The raw material monograph presents a method for determining the content of cefotaxime by HPLC using a $\mathrm{C}_{18}$ column in the dimensions $150 \times$ $3.9 \mathrm{~mm}^{2}, 5 \mu \mathrm{m}$ at $30^{\circ} \mathrm{C}$. Gradient mode was used by switching the proportions of mobile phases A $(0.05 \mathrm{M}$ phosphate buffer solution with $\mathrm{pH}$ adjusted to 6.25 with phosphoric acid and methanol 86:14 (V/V)) and B (0.05 M phosphate buffer solution with $\mathrm{pH}$ adjusted to 6.25 with phosphoric acid and methanol 60:40 (V/V)), with a flow rate of $1.0 \mathrm{~mL} / \mathrm{min}$. The detector used was a UV detector at $235 \mathrm{~nm}$. The determination of the 


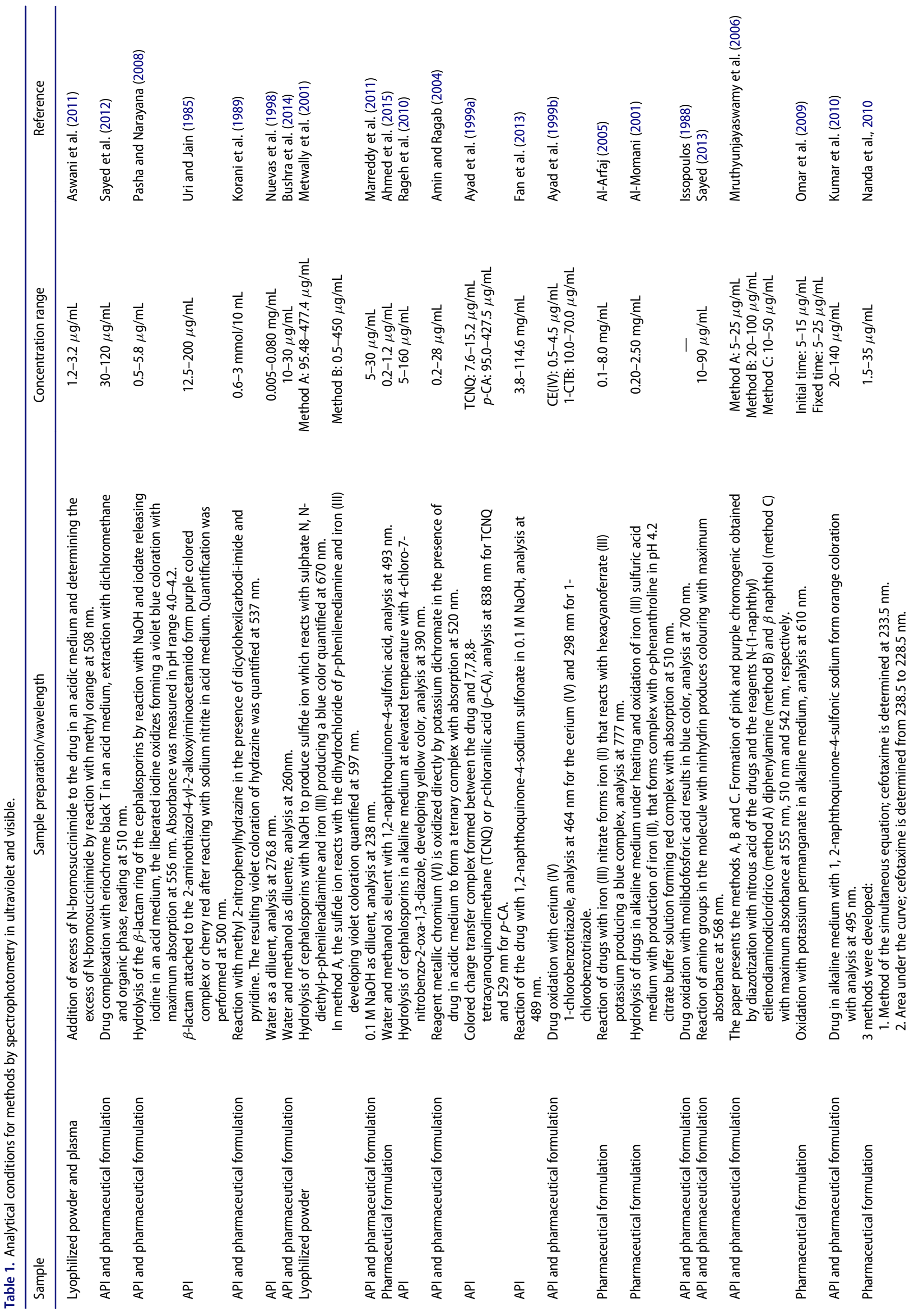



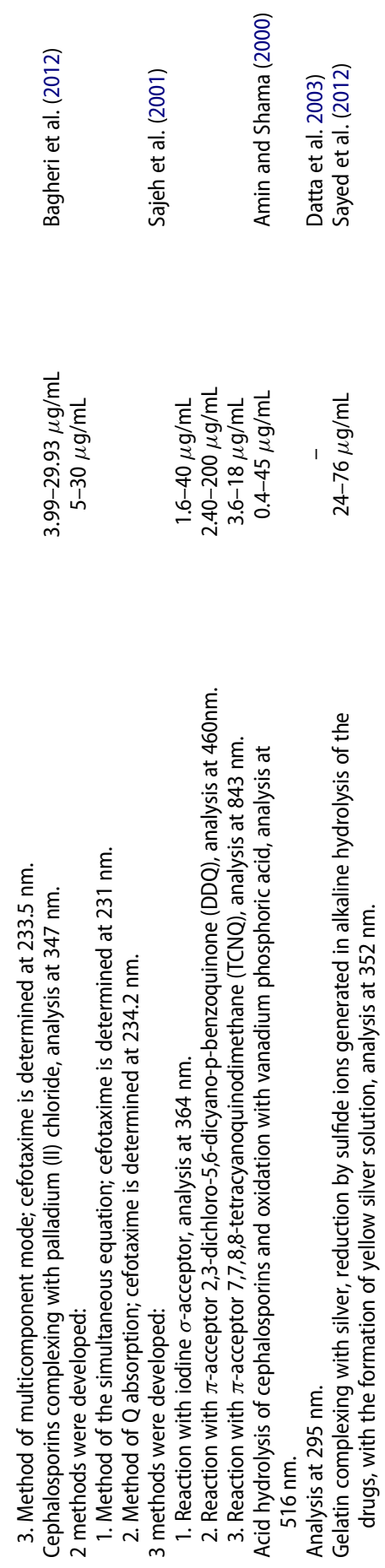

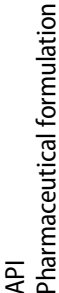

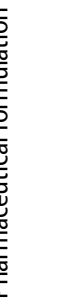

$\bar{q}$

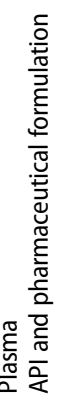




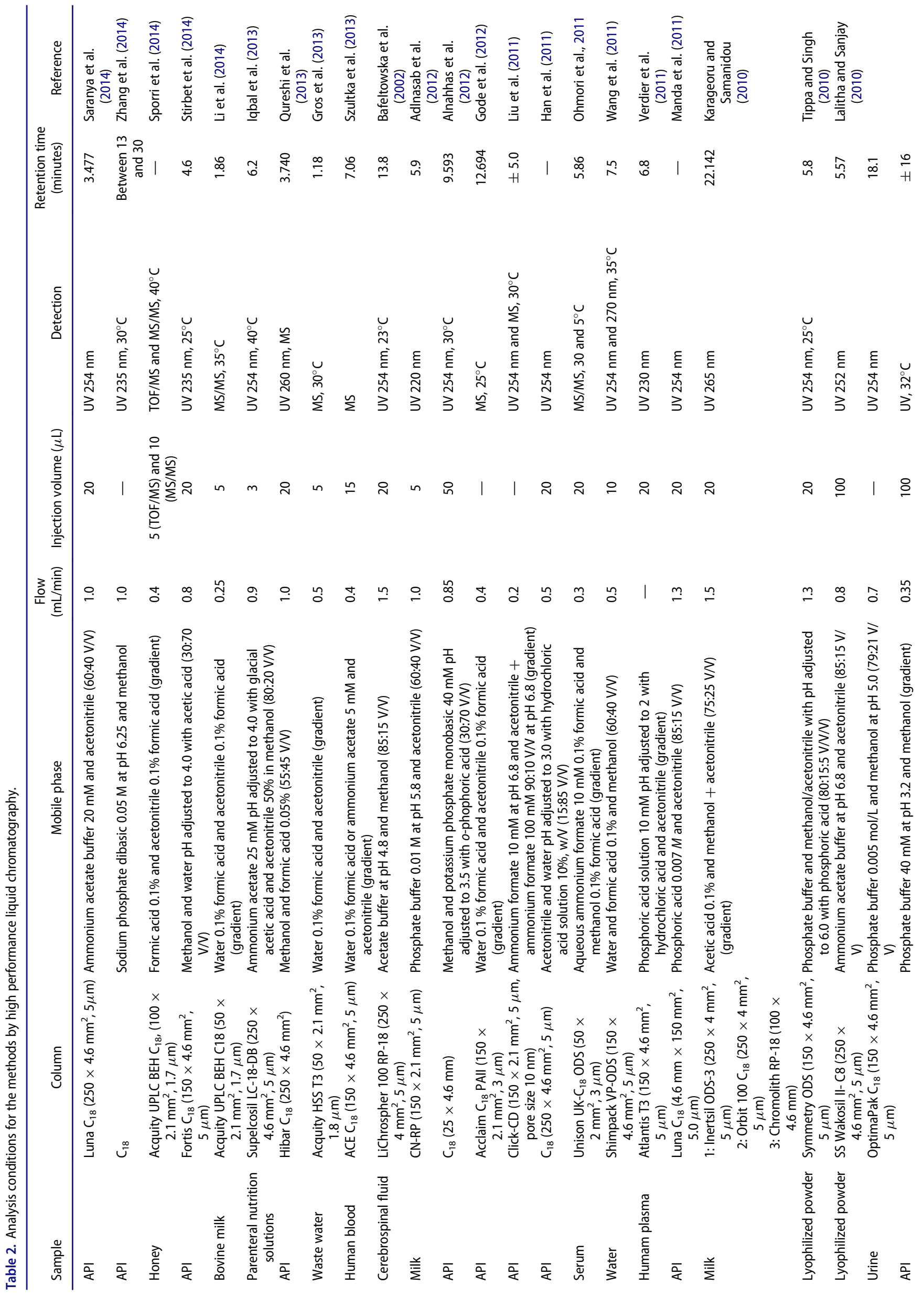




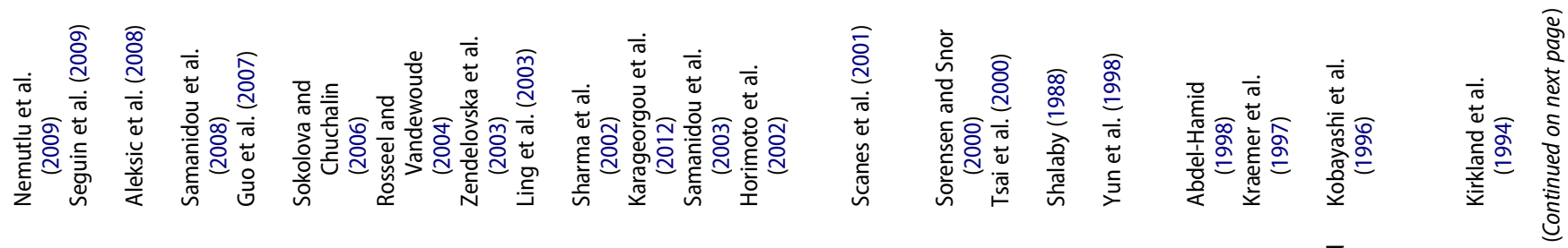

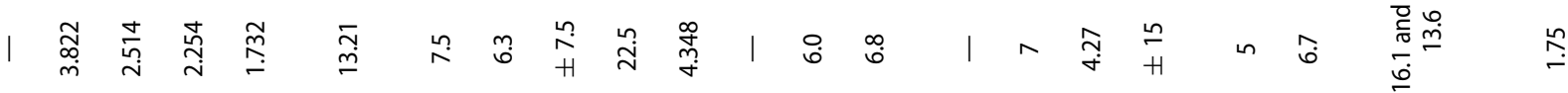

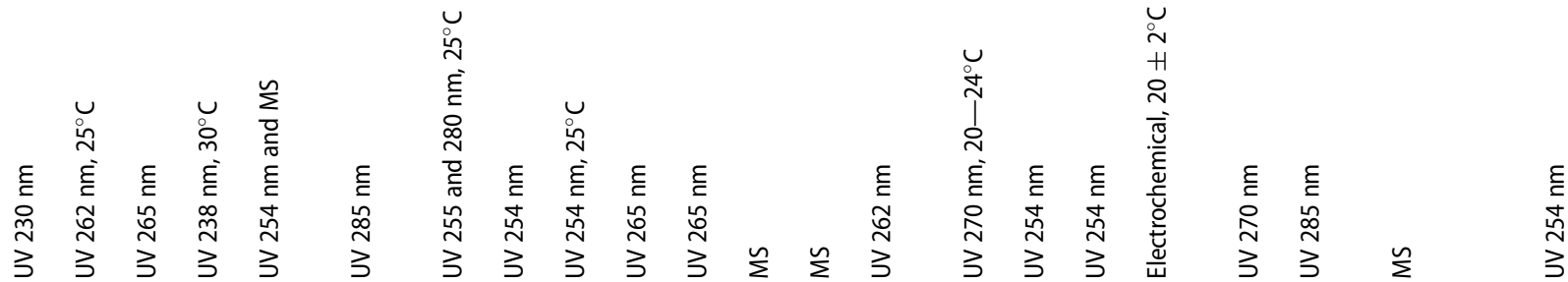

I 유

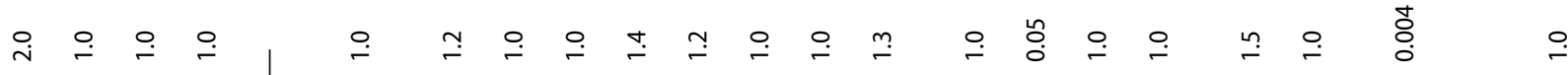

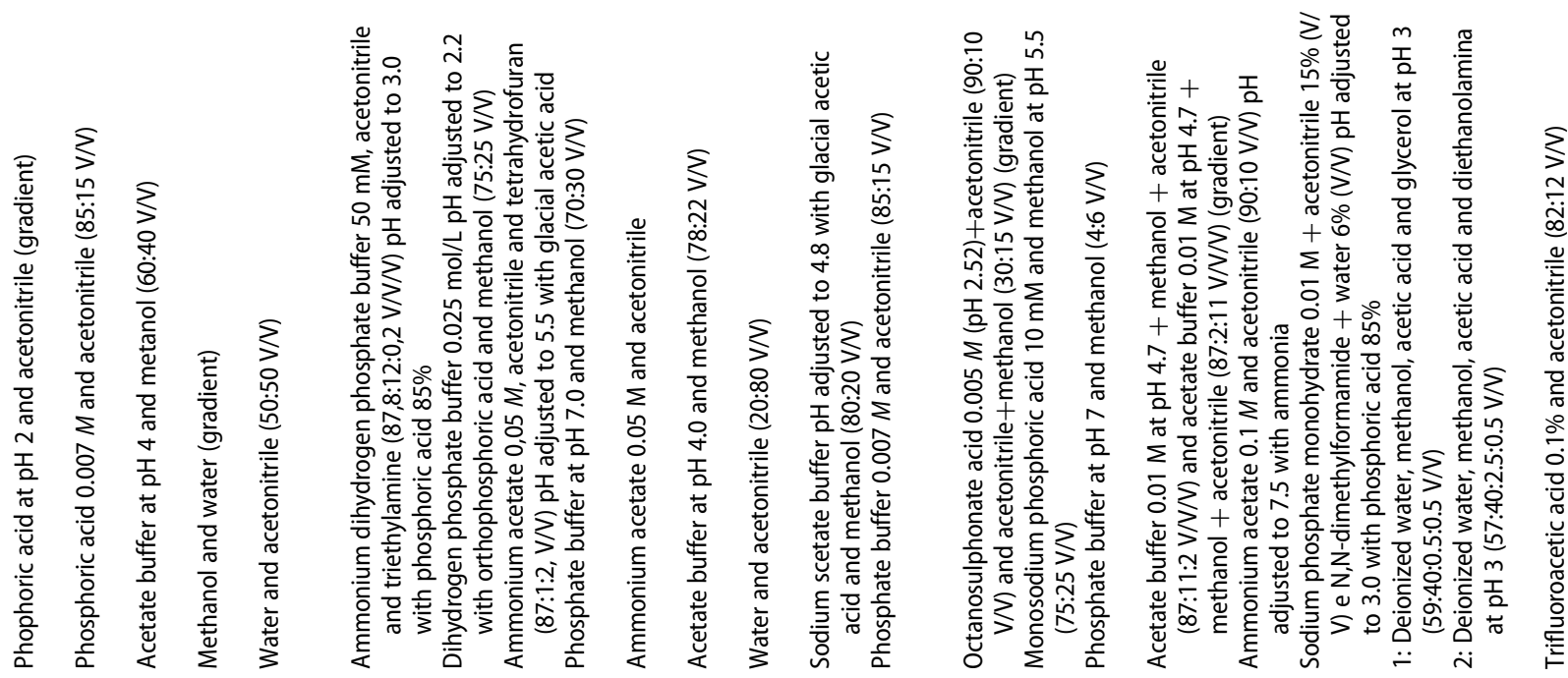

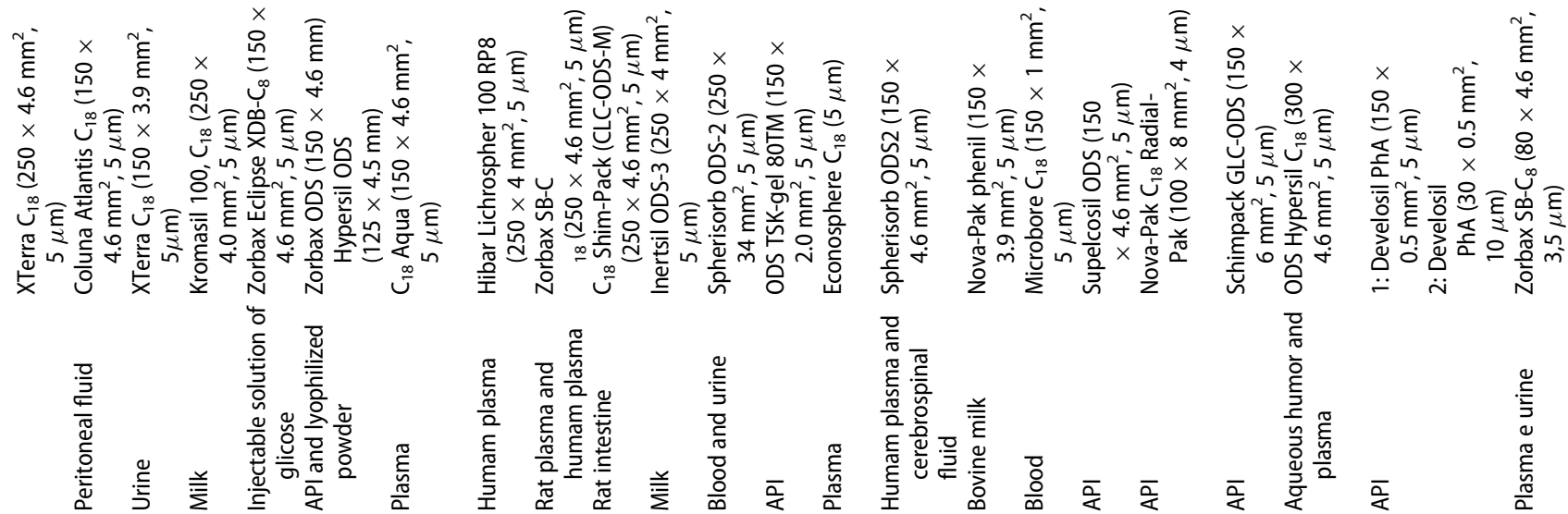




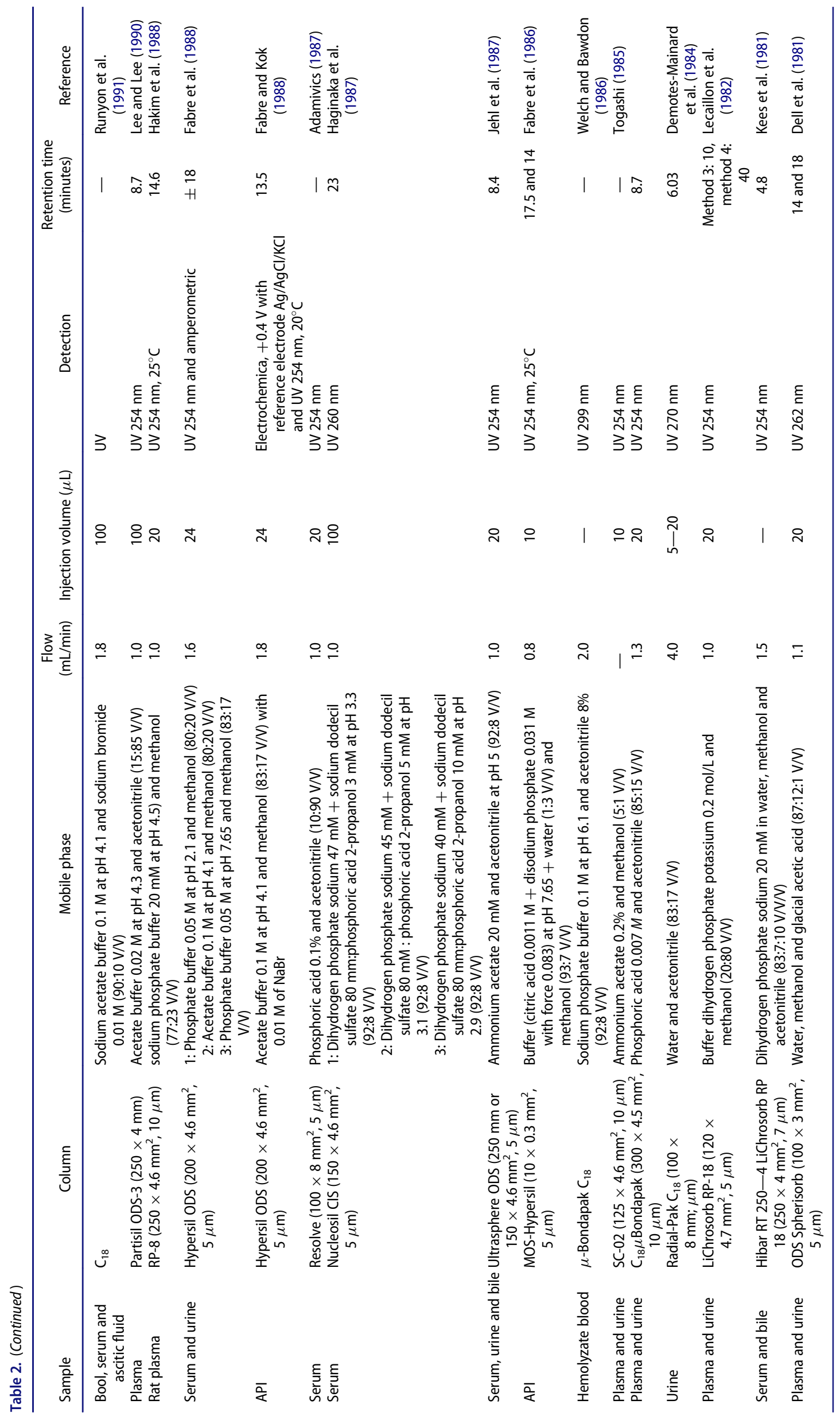


organic impurities content and the test for injectable solution and lyophilized powder for solution for injection are performed under the same conditions as the content for the raw material (United States Pharmacopeia Convention, 2014).

The British Pharmacopoeia presents monographs for API (active pharmaceutical ingrediente) and injectable solution. The monograph for API presents tests for assay and related substances by HPLC under the same analysis conditions: $\mathrm{C}_{18}$ column with dimensions $150 \times 3.9 \mathrm{~mm}^{2}, 5 \mu \mathrm{m}$, temperature of $30^{\circ} \mathrm{C}$, mobile phase buffer phosphate solution with $\mathrm{pH}$ adjusted to 6.25 with phosphoric acid and methanol with gradient elution, flow rate $1.0 \mathrm{~mL} / \mathrm{min}$ and a UV detector at $235 \mathrm{~nm}$. The monograph for the injectable solution includes related substances testing and content by HPLC analysis under the following conditions: C18 column with dimensions $250 \times 4.6 \mathrm{~mm}^{2}, 5$ $\mu \mathrm{m}$, temperature $25^{\circ} \mathrm{C}$, mobile phase phosphate buffer with $\mathrm{pH}$ adjusted to 7.0 with phosphoric acid and methanol 100 : $37.5(\mathrm{~V} / \mathrm{V})$, flow rate $1.0 \mathrm{~mL} / \mathrm{min}$ and a UV detector at $235 \mathrm{~nm}$ (The Stationary Office, 2014).

HPLC provides good precision and accuracy in the analysis. It is a separation technique and there are many possibilities of mobile phases, stationary phases and detectors, which permit an excellent selectivity and analysis of different compounds simultaneously. Among the methods for the drug in literature, the majority use buffer solution in the mobile phase, with consequent precipitation in the equipment and chromatographic column over time, reducing their life time and improving the analysis cost (Moreno and Salgado, 2008, 2012; Pedroso and Salgado, 2014; Rugani and Salgado, 2014).

The reported methods by spectrophotometry and HPLC for cefotaxime quantification use considerable amounts of toxic reagents and solvents by the operator and the environment, which have a great environmental impact considering the waste generatied. With the growing concern about these matters, exploring the reduction of the use of compounds that require waste treatment and great care for the operator's safety is increasingly demanded by pharmaceutical industries and academic analysis. Thus, the application of green chemistry, sustainability and reduced waste generation in analytical chemistry and quality control procedures is helpful for the preservation of the environment and to provide a better quality of life for analysts and for the population in general (Rodrigues and Salgado, 2016).

The HPLC and spectrophotometry techniques should be used with conscience by the analyst, trying to reduce the use of toxic reagents and solvents applying some of the principles of green chemistry, as using automatic and miniaturized methods, replace of toxic reagents and solvents, reducing the use of samples and the number of samples, avoiding sample treatment, when it is possible, and using sustentable, renewable and biodegradable solvents (Galuszka et al., 2013). Some alternative green solvents were reported in literature by Espino et al. (2016): ionic liquids, deep eutetic solventes and, recently, natural deep eutetic solvents, which have many advantages including biodegradability, low cost, low toxicity and sustainability. Other solvents such as water, ethanol, propanol and butanol should be used as an alternative (Welton, 2016).

One alternative technique of analytical method that can be employed in quantifying cefotaxime is the infrared spectroscopy. Consortti and Salgado (2017) developed and validated an analytical method for the quantification of cefotaxime in lyophilized powder by infrared spectroscopy as a green alternative to HPLC and spectrophotometry.

The method used the absorbance relative to the peak height in the region from 1825 to $1740 \mathrm{~cm}^{-1}$ in the sodium cefotaxime spectrum (relative to the stretching of the double bond between carbon and oxygen (carbonyl) of the lactam group. The method has low toxicity, cost, waste generation and toxicity for analyst, and it is able to quantify the drug with confidence, which makes it a green alternative method for use in quality control routine.

\section{Conclusion}

The development of an ideal antibiotic with high safety and efficacy and low toxicity and microorganism resistance remains a challenge.

This paper conducted a detailed critical review of the methods for the analysis of cefotaxime sodium in different matrices (such as plasma, serum, urine, milk and medicines) and a large number of methods employing HPLC and spectrophotometry in the UV and visible regions were observed.

Despite the advantages of the techniques and methods used, most of them include the use of toxic solvents introduced in the environment and to which the operator is exposed; in addition, they generate a large amount of waste. In light of the growing awareness of the need to adopt green procedures, developing new methods to reduce the use of these consumables and waste generation for pharmaceuticals analysis is of great value.

Relevant points to consider in the analytical methods for quantifying cefotaxime in biological matrices are the complexity, the amount of analyte and the need for sample treatment, usually with harmful solvents and reagents to operator and environment. It is not always possible to replace and reduce the use of these solvents and reagents and miniaturize the samples.

\section{ORCID}

Lívia Paganini Consortti (iD http://orcid.org/0000-0002-6937-9990

\section{References}

Abdel-Hamid, M. E. FSQ Spectrophotometric and HPLC Analysis of Some Cephalosporins in the Presence of their Alkali-Induced Degradation Products. Farmaco 1998, 53, 132-138.

Adamivics, J. A. Determination of Antibiotics and Antimicrobial Agents in Human Serum by Direct Injection onto Silica Liquid Chromatographic Columns. J. Pharm. Biomed. Anal. 1987, 5, 267-274.

Adlnasab, L.; Ebrahimzadeh, H.; Yamini, Y. A Three Phase Dispersive Liquid-Liquid Microextraction Technique for the Extraction of Antibiotics in Milk. Microchim. Adv. Acta. 2012, 179, 179-184.

Ahmed, S. M. A.; Elbashir, A. A.; Aboul-Enein, H. Y. New Spectrophotometric Method for Determination of Cephalosporins in Pharmaceutical Formulations. Arab. J. Chem. 2015, 8, 233-239.

Al-Arfaj, N. A. Spectrophotometeric Determination of Dome Dephalosporins in Pharmaceutical Formulations. J. Saudi Chem. Soc. 2005, 9, 225-236.

Aleksic, M. M.; Kapetanovic, V.; Atanackovic, J.; Jocic, B.; Zecevic, M. Simultaneous Determination of Cefotaxime and Desacetylcefotaxime in Real Urine Sample Using Voltammetric and High-Performance Liquid Chromatographic Methods. Talanta 2008, 77, 131-137. 
Alessio, P. V.; Salgado, H. R. N. Development and Validation of a Successful Microbiological Agar Assay for Determination of Ceftriaxone Sodium in Powder for Injectable Solution. Pharmaceutics 2012, 4, 334342.

Al-Momani, I. F. Spectrophotometric Determination of Selected Cephalosporins in Drug Formulations Using Flow Injection Analysis. J. Pharm. Biomed. Anal. 2001, 25, 751-757.

Alnahhas, B.; Hassan, A.; Alhosini, H. New Rapid and Validated Isocratic HPLC Method for Separation and Assay of Three 3rd Generation's Cephalosporins (ceftazidime, ceftriaxone, cefotaxime). Int. J. Pharm. Sci. Rev. Res. 2012, 14, 11, 50-56.

Amin, A. S.; Shama, S. A. Vanadophosphoric Acid as a Modified Reagent for the Spectrophotometric Determination of Certain Cephalosporins and Their Dosage Forms. Mon. Chem. 2000, 131, 313-319.

Amin, A. S.; Ragab, G. H. Spectrophotometric Determination of Certain Cephalosporins in Pure form and in Pharmaceutical Formulations. Spectrochim. Acta Part A 2004, 60, 2831-2835.

National Health Surveillance Agency (ANVISA). Resolution RDC 17, 16 April 2010: Technical Regulation of Good Manufacturing Practices of Drugs; Official Diary of the Union: Brasília, DF, April 19, 2010.

Nacional Health Surveillance Agency (ANVISA). List of Reference Medicines; ANVISA: Brazil. http://www.anvisa.gov.br/medicamentos/refer encia/lista.pdf Accessed on [16.10.2016], 2016.

Aswani, K. C. H.; Gurupada, B. M.; Navya, S. S. Determination and Validation of Cefadroxil, Ceftriaxone and Cefotaxime by Using n-Bromosuccinamide in Human Plasma and Pharmaceutical Dosage Form. Int. J. Res. Pharm. Sci. 2011, 2, 206-212.

Ayad, M. M.; Shalaby, A. A.; Abdellatef, H. E.; Elsaid, H. M. Spectrophotometric and Atomic Absorption Spectrometric Determination of Certain Cephalosporins. J. Pharm. Biomed. Anal. 1999a, 18, 975-983.

Ayad, M. M.; Shalaby, A. A.; Abdellatef, H. E.; Elsaid, H. M. Spectrophotometric Determination of Certain Cephalosporins Through Oxidation with Cerium(IV) and 1-Chlorobenzotriazole. J. Pharm. Biomed. Anal. 1999b, 20, 557-564.

Bafeltowska, J. J.; Buszmana, E.; Mandtb, K.; Hawranekb, J. Determination of Cefotaxime and Desacetylcefotaxime in Cerebrospinal Fluid by Solid-Phase Extraction and High-Performance Liquid Chromatography. J. Chromatogr. A 2002, 976, 249-254.

Bagheri, G. H. A.; Yosef, A. R.; Rezvani, M.; Roshanzamir, S. Spectrophotometric Complexation of Cephalosporins with Palladium (II) Chloride in Aqueous and Non-Aqueous Solventes. Spectrochim. Acta A: Mol. Biomol. Spectrosc. 2012, 89, 317-321.

Brito, M. A.; Cordeiro, B. C. Necessidade de novos antibióticos. J. Bras. Patolog. Med. Lab. 2012, 48, 247-249.

Brooks, B. D.; Brooks, A. E. Therapeutic Strategies to Combat Antibiotic Resistance. Adv. Drug Deliv. Rev. 2014, 78, 14-27.

Brunton, L. L.; Lazo, J. S.; Parker, K. L. Goodman \& Gilman: the Pharmacological Basis of Therapeutics; McGraw Hill: Rio de Janeiro, 2012.

Bushra, M. U.; Akter, N.; Hassan, M. R.; Islam, A.; Hossain, M. R. Development and Validation of a Simple UV Spectrophotometric Method for the Determination of Cefotaxime Sodium in Bulk and Pharmaceutical Formulation. IOSR J. Pharm. 2014, 4, 74-77.

Consortti, L. P.; Salgado, H. R. N. Green Method for Quantification of Sodium Cefotaxime in Lyophilized Powder by Infrared Spectroscopy. J. Pharm. Sci. Emerg. Drugs 2017, 5 (in press).

Council of Europe. European Pharmacopoeia; Council of Europe (EDQM), 2014; 8th ed.

Datta, B.; Mandal, T. K.; Chakraborty, A. K. Pharmacokinetics of Cefotaxime in Goats with Experimentally Induced Kidney Damage. Indian J. Pharmacol. 2003, 35, 173-176.

De Marco, B. A.; Salgado, H. R. N. Characteristics, Properties and Analytical Methods of Cefadroxil: A Review. Crit. Rev. Anal. Chem. 2016, 47, 93-98

Dell, D.; Chamberlain, J.; Coppin, F. Determination of Cefotaxime and Desacetilcefotaxime in Plasma and Urine by High-Performance Liquid Chromatography. J. Chromatogr. 1981, 226, 431-440.

Demotes-Mainard, F. M.; Vincon, G. A.; Jarry, C. H.; Albin, H. C. Micromethod for the Determination of Cefotaxime and Desacetylcefotaxime in Plasma and Urine by High-Performance Liquid Chromatography. J. Chromatogr. 1984, 336, 438-445.
Espino, M.; Fernández, M. A.; Gomez, F. J. V.; Silva, M. F. Natural Designer Solvents for Greening Analytical Chemistry. Trends Anal. Chem. 2016, 76, 126-136.

Fabre, H.; Blanchin, M. D.; Tjaden, U. High-Performance Liquid Chromatography with Anodic Amperometric Detection for the Determination of Cefotaxime and its Metabolites. J. Chromatogr. 1986, 111, 12811284 .

Fabre, H.; Blanchin, M.; Kok, W. T. Liquid Chromatography with Amperometric Detection for the Determination of Cephalosporins in Biological Fluids. Analyst 1988, 113, 651-655.

Fabre, H.; Kok, W. T. Determination of Cephalosporins and Decomposition Products by Liquid Chromatography with Indirect Electrochemical Detection. Anal. Chem. 1988, 60, 136-141.

Fan, B.; Gengb, M.; Wangb, Y.; Lia, Q. Spectrophotometric Determination of Cefotaxime by Using Sodium 1,2-Naphthoquinone-4-Sulfonate. $J$. Anal. Chem. 2013, 68, 965-968.

Fernandes, R.; Amador, P.; Prudêncio, C. $\beta$-Lactams: Chemical Structure, Mode of Action and Mechanisms of Resistance. Rev. Med. Microbiol. 2013, 24, 7-17.

Galuszka, A.; Migaszewski, Z.; Namiesnik, J. The 12 Principles of Green Analytical Chemistry and the SIGNIFICANCE Mnemonic of Green Analytical Practices. Trends Anal. Chem. 2013, 50, 78-84.

Gáspár, A. T.; Andrási, M.; Kardos, S. Application of Capillary Zone Electrophoresis to the Analysis and to a Stability Study of Cephalosporins. J. Chromatogr. B 2002a, 775, 239-246.

Gáspár, A; Kardoz, S.; Andrási, M.; Klekner, Á. Capillary Electrophoresis for the Direct Determination of Cephalosporins in Clinical Samples. Chromatogr. Suppl., 2002b, 56, 109-114.

Gode, D.; Martin, M. M.; Steiner, F.; Huber, C. G.; Volmer, D. A. Rapid narrow Band Elution for On-Line SPE Using a Novel Solvent Plug Injection Technique. Anal. Bioanal. Chem. 2012, 404, 433-445.

Gros, M.; Rodríger-Mozaz, S.; Barceló, D. Rapid Analysis of Multiclass Antibiotic Residues and Some of their Metabolites in Hospital, Urban Wastewater and River Water by Ultra-High-Performance Liquid Chromatography Coupled to Quadrupole-Linear ion Trap Tandem Mass Spectrometry. J. Chromatogr. A, 2013, 1292, 173-188.

Guimarães, D. O.; Momesso, L. S.; Pupo, M. T. Antibiotics: Therapeutic Importance and Prospects for the Discovery and Development of New Agents. New Chem. 2010, 33, 667-679.

Guo, P.; Li, X.; Wang, J.; You, A. Study on the Compatibility of Cefotaxime with Tinidazole in Glucose Injection. J. Pharm. Biomed. Anal. 2007, 43, 1849-1853.

Haginaka, J.; Wakai, J.; Yasuda, H.; Nakagawa, T. Direct Serum Injection with Micellar Liquid Chromatography: Chromatographic Behavior and Recovery of Cephalosporins. Anal. Chem. 1987, 59, 2732-2734.

Hakim, L.; Bourne, D. W. A.; Triggs, E. J. High-Performance Liquid Chromatographic Assay of Cefotaxime, Desacetylcefotaxime and Ceftriaxone in Rat Plasma. J. Chromatogr. 1988, 424, 111-117.

Han, D.; Wang, Y.; Jin, Y.; Row, K. H. Analysis of Some $\beta$-lactam Antibiotics Using Ionic Liquids as Mobile Phase Additives by RP-HPLC. $J$. Chromatogr. Sci. 2011, 49, 63-66.

Helaleh, M. I. H.; Abu-Namehe, S. M.; Jamhour, R. M. A. Q. Direct Titration and Indirect Spectrophotometric Determination of Selected Cephalosporins. Acta Polon. Pharm. Drug Res. 1998, 55, 93-97.

Horimoto, M. S.; Mayumi, T.; Aoe, K.; Nishimura, N.; Sato, T. Analysis of $\beta$-lactam Antibiotics by High Performance Liquid Chromatography Atmospheric Pressure Chemical Ionization Mass Spectrometry Using Bromoform. J. Pharm. Biomed. Anal. 2002, 30, 1093-1102.

Iqbal, M. S.; Bahari, M. B.; Darwis, Y.; Iqbal, M. Z.; Hayat, A. An RPHPLC-UV Method with SPE for Cefotaxime in all-in-one Total Parenteral Nutritional Admixtures: Application to Stability Studies. J. AOAC Int. 2013, 2, 290-294.

Infarmed. Portuguese Pharmacopeia Infarmed: Lisboa, 2005; 8th ed.

Issopoulos, P. B. Spectrophotometric Determination of Certain Cephalosporins using Molybdophosphoric Acid. Analyst 1988, 113 1083-1086.

Jehl, F.; Birckel, P.; Monteil, H. Hospital Routine Analysis of Penicillins, Thirdgeneration Cephalosporins and Aztreonam by Conventional and High-Speed High-Performance Liquid Chromatography. J. Chromatogr. 1987, 413, 109-119. 
Jones, R. N. Cefotaxime and Desacetylcefotaxime Antimicrobial Interactions. Diagn. Microbiol. Infect. Dis. 1995, 22, 19-33.

Karageorgou, E. G.; Samanidou, V. F. Application of Ultrasound-Assisted Matrixsolid-Phase Dispersion Extraction to the HPLC Confirmatory Determination of Cephalosporin Residues in Milk. J. Sep. Sci. 2010, 33, 2862-2871.

Karageorgou, E. G.; Samanidou, V. F.; Papadoyannis, I. N. UltrasoundAssisted Matrix Solid Phase Dispersive Extraction for the Simultaneous Analysis of $\beta$-Lactams (four Penicillins and Eight Cephalosporins) in Milk by High Performance Liquid Chromatography with Photodiode Array Detection. J. Sep. Sci. 2012, 35, 2599-2607.

Kees, F.; Strehl, E.; Seeger, K.; Seidel, G.; Dominiak, P.; Grobecker, H. Comparative Determination of Cefotaxime and Desacetyl Cefotaxime in Serum and Bile by Bioassay and High-Performance Liquid Chromatography. ArznemittelForsch. Drug Res. 1981, 31, 362-365.

Kirkland, K. M.; McCombs, D. A.; Kirkland, J. J. Rapid, High-Resolution High-Performance Liquid Chromatographic Analysis of Antibiotics. J. Chromatogr. A 1994, 660, 327-337.

Ko, R. J.; Sattler, F. R.; Nichols, S.; Akriviadis, E.; Runyon, B.; Appleman, M; Cohen, J. L.; Koda, R. T. Pharmacokinetics of Cefotaxime and Desacetylcefotaxime in Patients with Liver Disease. Antimicrob. Agents Chemother. 1991, 35, 1376-1380.

Kobayashi, K.; Sato, K.; Mizuno, Y.; Katsumata, Y. Capillary High-Performance Liquid Chromatography-Fast Atom Bombardment Mass Spectrometry of 24 Cephem Antibiotics. J. Chromatogr. B, 1996, 677, 275290.

Korani, M. A.; Abdel-Hay, M. H.; Bedair, M. M.; Gazy, A. A. Colorimetric Determination of Some Penicillins and Cephalosporins with 2-Nitrophenylhydrazine Hydrochloride. Talanta 1989, 36, 1253-1257.

Korolkovas, A. Dicionário Terapêutico Guanabara; Guanabara Koogan: Rio de Janeiro, 2010.

Kraemer, H.; Gehrke, R.; Breithaupt, A.; Breithaupt, H. Simultaneous Quantification of Cefotaxime, Desacetylcefotaxime, Ofloxacin and Ciprofloxacin in Ocular Aqueous Humor and in Plasma by High-Performance Liquid Chromatography. J. Chromatogr. B, 1997, 700, 147-153.

Kumar, C. H. A.; Kumar, T. A.; Gurupadayya, B. M.; Sloka, S. N.; Reddy, M. B. R. Novel Spectrophotometric Determination of Valacyclovir and Cefotaxime Using 1, 2-Napthaquinone-4-Sulfonic Acid Sodium in Bulk and Pharmaceutical Dosage Form. Arch. Appl. Sci. Res. 2010, 2, 278-287.

Lalitha, N.; Sanjay, P. P. N. Development and Validation of RP-HPLC Method for Estimation of Cefotaxime Sodium in Marketed Formulations. J. Basic Clin. Pharm. 2010, 1, 26-28.

Lecaillon, J. B.; Rouan, M. C.; Souppart, C.; Febvre, N.; Juge, F. Determination of Cefsulodin, Cefotian, Cephalexin, Cefotaxime, Desacetyl-Cefotaxime, Cefuroxime and Cefroxadin in Plasma and Urine by HighPerformance Liquid Chromatography. J. Chromatogr. 1982, 228, 257267.

Lee, Y. J.; Lee, H. S. Simultaneous Determination of Cefoxitin, Cefuroxime, Cephalexin and Cephaloridine in Plasma Using HPLC and a ColumnSwitching Technique. Chromatographia 1990, 30, 80-84.

Li, N.; Feng, F.; Yang, B.; Jiang, P.; Chu, X. Simultaneous Determination of $\beta$-Lactam Antibiotics and $\beta$-Lactamase Inhibitors in Bovine Milk by Ultra Performance Liquid Chromatography-Tandem Mass Spectrometry. J. Chromatogr. B, 2014, 945-946, 110-114.

Lin, C.; Chen, H.; Lin, E. C.; Lin, K.; Huang, H. Optimization of Separation and Migration Behavior of Cephalosporins in Capillary Zone Electrophoresis. J. Chromatogr. A 2000, 879, 197-210.

Ling, S. S. N.; Yuen, K. H.; Barker, S. A. Simple Liquid Chromatographic Method for the Determination of Cefotaxime in Human and Rat Plasma. J. Chromatogr. B 2003, 783, 297-301.

Liu, Q.; Xu, L.; Ke, Y.; Jin, Y.; Zhang, F.; Liang, X. Analysis of Cephalosporins by Hydrophilic Interaction Chromatography. J. Pharm. Biomed. Anal. 2011, 54, 623-628.

Manda, P.; Hargett, J. K.; Vaka, S. R. K.; Repka, M. A.; Murthyl, S. N. Delivery of Cefotaxime to the Brain via Intranasal Administration. Drug Dev. Ind. Pharm. 2011, 37, 1306-1310.

Marreddy, J. L.; Revathi, R.; Marreddy, S. N. R. Effective Quantitation of Cefotaxime Sodium in Bulk and Pharmaceutical Dosage forms Using Spectroscopy. Int. J. Pharm. Sci. Rev. Res. 2011, 9, 104-106.
Metwally, F. H.; Alwarthan, A. A.; Al-Tammi, S. A. Flow-Injection Spectrophotometric Determination of Certain Cephalosporins Based on the Formation of Dyes. Farmaco 2001, 56, 601-607.

Metz, P.; Kohlhepp, S. J.; Gilbert, D. N. Study of Different Off-Line Sample Processing Procedures and the Measurement of Antibiotic and Antiviral Levels in Human Serum by High-Performance Liquid Chromatography. J. Chromatogr. B 2002, 773, 159-166.

Moreno, A. H.; Salgado, H. R. N. Spectrophotometric Determination of Ceftazidime in Pharmaceutical Preparations Using Neocuproin as a Complexing Agent. Anal. Lett. 2008, 41, 2143-2152.

Moreno, A. H.; Salgado, H. R. N. Development and Validation of HPLC Method for Determination of Ceftazidime. J. AOAC Int. 2008, 91, 739743.

Moreno, A. H.; Salgado, H. R. N. Rapid and Selective UV Spectrophotometric Method for the Analysis of Ceftazidime. J. AOAC Int. 2009, 92, $820-823$

Moreno, A. H.; Salgado, H. R. N. Stability Study and Degradation Kinetics of Ceftazidime in Pharmaceutical Preparations. Adv. Anal. Chem. 2012, 2(1), 1-5.

Mrestani, Y.; Neubert, R.; Hartl, A.; Wohlrab, J. Determination of Cephalosporins in Urine and Bile by Capillary Zone Electrophoresis. Anal. Chim. Acta 1999, 349, 207-213.

Mrestrani, Y.; Neubert, R.; Schiewe, J.; Hartl, A. Application of Capillary Zone Electrophoresis in Cephalosporin Analysis. J. Chromatogr. B 1997, 690, 321-326.

Mruthyunjayaswamy, B. H. M.; Hiremath, B.; Malipatil, S. M.; Raju, S. A Simple and Sensitive Spectrophotometric Methods for the Determination of Cefotaxime Sodium. J. Indian Council Chem. 2006, 23, 120-123.

Nanda, R. K.; Bhagwat, V. V.; Potawale, S. E.; Vidyasagar, N. C.; Mishra, R. Simultaneous Spectrophotometric Estimation of Cefotaxime Sodium and Sulbactam Sodium in Pharmaceutical Dosage Form. Int. J. ChemTech Res. 2010, 2, 1612-1617.

Nassar, M. W. I.; Abd El-Sattar, O. I.; Barakat, S. E. M. Colorimetric and Titrimetric Determination of Cefotaxime Sodium in Bulk Powder and Pharmaceutical Formulations. Egypt. J. Pharm. Sci. 1996, 37, 175-187.

Nemutlu, E.; Kira, S.; Katlanb, D.; Beksac, M. S. Simultaneous Multiresponse Optimization of an HPLC Method to Separate Seven Cephalosporins in Plasma and Amniotic Fluid: Application to Validation and Quantification of Cefepime, Cefixime and Cefoperazone. Talanta 2009, 80, 117-126.

Nuevas, L.; González, R.; Rodríguez, J. C.; Hoogmartens, J. Derivative Spectrophotometric Determination of the Triethylammonium Salt of Cefotaxime in Presence of Related Compounds from the Synthesis. J. Pharm. Biomed. Anal. 1998, 18, 579-583.

Ohmori, T.; Suzuki, A.; Niwa, T.; Ushikoshi, H.; Shirai, K.; Yoshida, S.; Ogura, S.; Itoh, S. Simultaneous Determination of Eight $\beta$-lactam Antibiotics in Human Serum by Liquid Chromatography-Tandem Mass Spectrometry. J. Chromatogr. B 2011, 879, 1038-1042.

Oldifield, E.; Feng, X. Resistance-Resistant Antibiotics. Trends Pharmacol. Sci. 2014, 35, 664-674.

Omar, A. M.; Abdelmageed, O. H.; Attia, T. Z. Kinetic Spectrophotometric Determination of Certain Cephalosporins in Pharmaceutical Formulations. Int. J. Anal. Chem. 2009, 2009, 1-12.

O’Neil, M. J. (Ed.) The Merck Index: An Encyclopedia of Chemical, Drugs and Biologicals; RSC Publishing: Cambridge, 2013.

Pasha, C.; Narayana, B. A simple method for the Spectrophotometric Determination of Cephalosporins in Pharmaceuticals Using Variamine Blue. Eclét. Quím. 2008, 33, 41-46.

Patel, K. B.; Nicolau, D. P.; Nightingale, C. H.; Quintiliani, R., Pharmacokinetics of Cefotaxime in Healthy Volunteers and Patients. Diagn. Microbiol. Infect. Dis. 1995, 22, 49-55.

Patrick, G. L. An Introduction to Medicinal Chemistry; Oxford University Press: New York, 2009.

Pedroso, T. M.; Salgado, H. R. N. Validation of Analytical Methodology for Quantification of Cefazolin Sodium by Liquid Chromatography to be Applied for Quality Control in Pharmaceutical Industry. Braz. J. Pharm. Sci. 2014, 50, 213-223.

Penalvo, G. C.; Julien, E.; Fabre, H. Cross Validation of Capillary Electrophoresis and High-Performance Liquid Chromatography for Cefotaxime and Related Impurities. Chromatographia 1996, 42, 159-164. 
Penalvo, G. C.; Kelly, M.; Maillols, H.; Fabre, H. Evaluation of Capillary Zone Electrophoresis and Micellar Electrokinetic Capillary Chromatography with Direct Injection of Plasma for the Determination of Cefotaxime and its Metabolite. Anal. Chem. 1997, 69, $1364-1369$

Qureshi, T.; Memon, N.; Memon, S. Q.; Abro, K.; Shah, S. W. LC/UV Determination of Cefradine, Cefuroxime, and Cefotaxime in Dairy Milk, Human Serum and Wastewater Samples. Springer Plus 2013, 2, $1-8$.

Rageh, A. H.; El-Shaboury, S. R.; Saleh, G. A.; Mohamed, F. A. Spectophotometric Method for Determination of Certain Cephalosporins Using 4-Chloro-7-Nitrobenzo-2-Oxa-1,3-Diazole (NBD-Cl). Nat. Sci. 2010, 2, 828-840.

Raut, M. D.; Ghode, S. P.; Kale, R. S.; Puri, M. V.; Patil, H. S. Spectrophotometric Method for the Simultaneous Estimation of Cefotaxime Sodium and Sulbactum in Parentral Dosage Forms. Int. J. ChemTech Res. 2011, 3, 1506-1510.

Rodrigues, D. F.; Salgado, H. R. N. Development and Validation of a Green Analytical Method of RP-HPLC for Quantification Cefepime Hydrochloride in Pharmaceutical Dosage Forms: Simple, Sensitive and Economic. Curr. Pharm. Anal. 2016, 12, 306-314.

Rosseel, M. T.; Vandewoude, K. H. Liquid Chromatographic Determination of the Plasma Concentrations of Cefotaxime and Desacetylcefotaxime in Plasma of Critically ill Patients. J. Chromatogr. B, 2004, 811, 159-163.

Rugani, K. S.; Salgado, H. R. N. Stability-Indicating LC Method for the Determination of Cephalothin in Lyophilized Powder for Injection. Anal. Methods 2014, 6, 4437-4445.

Runyon, B. A.; Akriviadis, E. A.; Sattler, F. R.; Cohen, J. Ascitic Fluid and Serum Cefotaxime and Desacetyl Cefotaxime Levels in Patients Treated for Bacterial Peritonitis. Dig. Dis. Sci. 1991, 36, 1782-1786.

Sajeh, G. A.; Askal, H. F.; Radwan, M. F.; Omar, M. A. Use of ChargeTransfer Complexation in the Spectrophotometric Analysis of Certain Cephalosporins. Talanta 2001, 54, 1205-1215.

Samanidou, V. F.; Hapeshi, E.A.; Papadoyannis, I. N. Rapid and Sensitive High-Performance Liquid Chromatographic Determination of Four Cephalosporin Antibiotics in Pharmaceuticals and Body Fluids. J. Chromatogr. B 2003, 788, 147-158.

Samanidou, V. F.; Tsochatzis, E. D.; Papadoyannis, I. N. HPLC Determination of Cefotaxime and Cephalexine Residues in Milk and Cephalexine in Veterinary Formulation. Microchim. Acta. 2008, 160, 471-475.

Saranya, C. H. L.; Thejaswini, J. C.; Gurupadayya, B. M.; Sruthi, B. Y. K. Simultaneous Determination of Cefotaxime Sodium and Paracetamol by LC-MS. IOSR J. Pharm. 2014, 4, 12-18.

Sayed, R. A. Spectrophotometric Method for the Determination of Cefotaxime Sodium and Cefoperazone Sodium in Pure and Pharmaceutical Dosage Forms. Am. Chem. Sci. J. 2013, 3, 514-525.

Sayed, R. A.; Hassan, W. S.; El-Mammli, M. Y.; Shalabya, A. A. New extractive Spectrophotometric Method for the Determination of Gatifloxacin and Cefotaxime Sodium in Pure and Pharmaceutical Dosage Forms. Orient. J. Chem. 2012, 28, 639-650.

Sayed, R. A.; Hassan, W. S.; El-Mammli, M. Y.; Shalaby, A. Use of Silver-Gelatin Complex for the Determination of Cefoperazone Sodium, Ceftazidime Pentahydrate and Cefotaxime Sodium in Pure and Pharmaceutical Dosage Forms. Chem. Sci. Rev. Lett. 2013, 1, $10-17$.

Scanes, T.; Hundt, A. F.; Swart, K. J.; Hundt, H. K. L. Simultaneous Determination of Cefotaxime and Desacetylcefotaxime in Human Plasma and Cerebrospinal Fluid by High-Performance Liquid Chromatography. J. Chromatogr. B 2001, 750, 171-176.

Seguin, P.; Verdir, M. C.; Chanavaz, C.; Engrand, C.; Laviolle, B.; Donnio, P.; Mallédant, Y. Plasma and Peritoneal Concentration Following Continuous Infusion of Cefotaxime in Patients with Secondary Peritonitis. J. Antimicrob. Chemother. 2009, 63, 564-567.

Shalaby, A. Simple HPLC Method for the Analysis of Some Pharmaceuticals. J. Liq. Chromatogr. Relat. Technol. 1988, 21, 3161-3171.

Sharma, P.; Chawla, H. P. S.; Panchagnula, R. LC Determination of Cephalosporins in in vitro Rat Intestinal Sac Absorption Model. J. Pharm. Biomed. Anal. 2002, 27, 39-50.
Society of Japanese Pharmacopoeia. Japanese Pharmacopoeia. Society of Japanese Pharmacopoeia: Tokyo, 2011; 16th ed.

Sokolova, L. I.; Cchuchalina, I. V. Preconcentration of the Antibiotics Cephazolin, Cefotaxime, and Levomycetin on Modified Silicas. J. Anal. Chem. 2006, 61, 1140-1143.

Solangi, A. R.; Memon, S. Q.; Khuhawar, M. Y.; Nhanger, M. I. Quantitative Analysis of Eight Cephalosporin Antibiotics in Pharmaceutical Products and Urine by Cappilary Zone Electrophoresis. Acta Chromatogr. 2007, 19, 81-96.

Sorensen, L. K.; Snor, L. K. Determination of Cephalosporins in Raw Bovine Milk by High-Performance Liquid Chromatography. J. Chromatogr. A 2000, 882, 145-151.

Sporri, A. S.; Jana, P.; Cognard, E.; Ortelli, D.; Edder, P. Comprehensive Screening of Veterinary Drugs in Honey by Ultra-High-Performance Liquid Chromatography Coupled to Mass Spectrometry. Food Addit. Contam.: Part A, 2014, 31, 806-816.

Stirbet, D.; Litescu, S.; Radu, G. Chromatographic Analysis of Immobilized Cefotaxime. J. Serb. Chem. Soc. 2014, 79, 579-586.

Szultka, M.; Krzeminski, R.; Jackowski, M.; Buszewski, B. Simultaneous Determination of Selected Chemotherapeutics in Human Whole Blood by Molecularly Imprinted Polymers Coated Solid Phase Microextraction Fibers and Liquid Chromatography-Tandem Massspectrometry. $J$ Chromatogr. B 2013, 940, 66-76.

The Stationery Office. British Pharmacopoeia; The Stationery Office: London, 2014.

Tippa, D. M. R.; Singh, N. Cefotaxime Sodium for Injection Reconstitution Stability Study in Intravenous and Intramuscular Diluents. Der Pharm. Sin. 2010, 1, 113-121.

Togashi, O. Pharmacokinetic Study of Cefotaxime (CTX) in Dogs. Pharm. Res. 1985, 124-130.

Tortora, G. J.; Funke, B. R.; Case, C. L. Microbiologia; Artmed: Porto Alegre, 2012.

Tsai, T. H.; Chen, Y. F.; Chen, K. C.; Shum, A. Y. C.; Chen, C. F. Concurrent Quantification and Pharmacokinetic Analysis of Cefotaxime in Rat Blood and Brain by Microdialysis and Microbore Liquid Chromatography. J. Chromatogr. B 2000, 738, 75-81.

United States Pharmacopoeia Convention. The United States Pharmacopeia; United States Pharmacopoeia Convention: Rockville, 2014; 37th ed.

Uri, J. V.; Jain, T. C. Colorimetric Detection and Spectrophotometric Determination of the Aminothiazolyl-Alkoxyimino $\beta$-Lactams. J. Antibiot. 1985, 39, 669-675.

Verdier, M.; Tribut, O.; Tattevin, P.; Tulzo, T. L.; Michelet, C.; Bentué-Ferrer, D. Simultaneous Determination of $12 \beta$-Lactam Antibiotics in Human Plasma by High-Performance Liquid Chromatography with UV Detection: Application to Therapeutic Drug Monitoring. Antimicrob. Agents Chemother. 2011, 55, 4873-4879.

Vieira, D. C. M.; Ricarte, P. C.; Salgado, H. R. N. Development and Validation of the Quantitative Analysis of Cefuroxime Sodium in Powder for Injection by Infrared Spectroscopy. Adv. Anal. Chem. 2012, 6, 80-87.

Vieira, D.C.M.; Salgado, H. R. N. Comparison of HPLC and UV Spectrophotometric Methods for the Determination of Cefuroxime Sodium in Pharmaceutical Products. J. Chromatogr. Sci. 2011, 49, 508-511.

Wang, P.; Yuan, T.; Hu, J.; Tan, Y. Determination of Cephalosporin Antibiotics in Water Samples by Optimised Solid Phase Extraction and High Performance Liquid Chromatography with Ultraviolet Detector. Int. J. Environ. Anal. Chem. 2011, 91, 1267-1281.

Wang, R.; Jia, Z.; Fan, J.; Jun, M.; Hua, X.; Zhang, Q.; Wang, G J. Separation and Determination of Cefotaxime Enantiomers in Injections by Capillary Zone Electrophoresis. Pharmazie 2009, 64, 156160.

Welch, W. D.; Bawdon, R. E. Cefotaxime Metabolism by Hemolyzed Blood: Quantitation and Inhibition of the Deacetylation Reaction. Diagn. Microbiol. Infect. Dis. 1986, 4, 119-124.

Welton, T. Solvents and Sustainable Chemistry. Proc. R. Soc. A 2016, 471, $1-26$.

Yllmaz, N.; Biryol, I. Anodic Voltammetry of Cefotaxime. J. Pharm. Biomed. Anal. 1998, 17, 1335-1344. 
Yun, E. K.; Prince, A. J.; Mcmillin, J. E.; Welch, L. E. High-Performance Liquid Chromatographic Separation and Electrochemical Detection of Cephalosporins. J. Chromatogr. B 1998, 712, 145-152.

Zendelovska, D.; Stafilov, T.; Milosevski, P. High-Performance Liquid Chromatographic Method for Determination of Cefixime and
Cefotaxime in Human Plasma. Bull. Chem. Technol. Maced. 2003, 22, 39-45

Zhang, W.; Hu, Q.; Zhang, X.; Li, Y.; Wang, M.; Hu, C. The Selection of Suitable Columns for a Reversed-Phase Liquid Chromatographic Separation of Beta-Lactam Antibiotics and Related Substances via Chromatographic Column Parameters. J. Chromatogr. A 2014, 1323, 87-96. 